\title{
Broadening International Perspectives on the Legal Environment for Personnel Selection
}

\author{
BRETT MYORS \\ Griffith University \\ FILIP LIEVENS, EVELINE \\ SCHOLLAERT, AND \\ GREET VAN HOYE \\ Ghent University \\ STEVEN F. CRONSHAW \\ University of Northern British Columbia \\ ANTONIO MLADINIC AND \\ VIVIANA RODRÍGUEZ \\ Pontificia Universidad Católica de Chile \\ HERMAN AGUINIS \\ University of Colorado at Denver \\ DIRK D. STEINER AND \\ FLORENCE ROLLAND \\ Université de Nice-Sophia Antipolis \\ HEINZ SCHULER \\ University of Hohenheim \\ ANDREAS FRINTRUP \\ HR Diagnostics \\ IOANNIS NIKOLAOU AND \\ MARIA TOMPROU \\ Athens University of Economics and \\ Business \\ S. SUBRAMONY AND SHABU B. RAJ \\ Defence Institute of Psychological \\ Research \\ SHAY TZAFRIR \\ University of Haifa \\ PETER BAMBERGER \\ Technion-Israel Institute of Technology \\ MARILENA BERTOLINO \\ University of Trento
}

\author{
MARCO MARIANI \\ University of Bologna \\ FRANCO FRACCAROLI \\ University of Trento \\ TOMOKI SEKIGUCHI \\ Osaka University \\ BETTY ONYURA \\ University of Guelph \\ HYUCKSEUNG YANG \\ Yonsei University \\ NEIL ANDERSON AND \\ ARNE EVERS \\ University of Amsterdam \\ OLEKSANDR CHERNYSHENKO \\ University of Canterbury \\ PAUL ENGLERT \\ OPRA Consulting Group \\ HENNIE J. KRIEK \\ SHL and University of South Africa \\ TINA JOUBERT \\ SHL \\ JESÚS F. SALGADO \\ University of Santiago de Compostela \\ CORNELIUS J. KÖNIG AND \\ LARISSA A. THOMMEN \\ Universität Zürich \\ AICHIA CHUANG \\ National Taiwan University \\ HANDAN KEPIR SINANGIL \\ Marmara University \\ MAHMUT BAYAZIT \\ Sabanci University
}


MARK COOK

University of Wales

\section{WINNY SHEN AND PAUL R. SACKETT University of Minnesota}

Brett Myors, School of Psychology, Griffith University; Filip Lievens, Eveline Schollaert, and Greet Van Hoye, Department of Personnel Management and Work Organizational Psychology, Ghent University; Steven F. Cronshaw, School of Business, University of Northern British Columbia; Antonio Mladinic and Viviana Rodríguez, Department of Psychology, Pontificia Universidad Católica de Chile; Herman Aguinis, The Business School, University of Colorado Denver; Dirk D. Steiner and Florence Rolland, Laboratoire de Psychologie Cognitive et Sociale, Université de Nice-Sophia Antipolis; Heinz Schuler, University of Hohenheim; Andreas Frintrup, HR Diagnostics; loannis Nikolaou and Maria Tomprou, Department of Management Science and Technology, Athens University of Economics and Business; S. Subramony and Shabu B. Raj, Defence Institute of Psychological Research; Shay Tzafrir, Department of Human Services, University of Haifa; Peter Bamberger, Davidson Faculty of Industrial Engineering and Management, Technion: Israel Institute of Technology; Marilena Bertolino, Department of Cognitive Science and Education, University of Trento; Marco Mariani, Department of Educational Science, University of Bologna; Franco Fraccaroli, Department of Cognitive Science and Education, University of Trento; Tomoki Sekiguchi, Graduate School of Economics, Osaka University; Betty Onyura (Kenya), Department of Psychology, University of Guelph; Hyuckseung Yang, Department of Management, Yonsei University; Neil Anderson and Arne Evers, University of Amsterdam; Oleksandr Chernyshenko, University of Canterbury; Paul Englert, OPRA Consulting Group; Hennie J. Kriek, Research and Development, SHL and Department of Industrial and Organizational Psychology, University of South Africa; Tina Joubert, SHL; Jesús F. Salgado, Departmento de Psicologia Social, University of Santiago de Compostela; Cornelius J. König and Larissa A. Thommen, Psychologisches Institut, Universität Zürich; Aichia Chuang, National Taiwan University; Handan Kepir Sinangil, Business Administration Department, Organizational Behavior Division, Marmara University; Mahmut Bayazit, Department of Management, Sabanci University; Mark Cook, University of Wales; Winny Shen and Paul R. Sackett, Department of Psychology, University of Minnesota.

Oleksandr Chernyshenko is now at the Nanyang Business School, Nanyang Technological University, Singapore.

This research was conducted while Antonio Mladinic was on leave from the Pontificia Universidad Católica de Chile and holding a visiting appointment at the University of Texas at El Paso, Herman Aguinis was on sabbatical leave from the University of Colorado Denver and holding a visiting appointment at the University of Salamanca (Spain) and the University of Puerto Rico, and Hyuckseung Yang was on sabbatical leave from Yonsei University and holding a visiting appointment at the University of Maryland. Authors from each country contributed equally to this article. Author names are ordered within country, with countries listed in alphabetical order.
We are pleased that our article (Myors et al., 2008) prompted this most useful set of commentaries. The goal of our article was to highlight similarities and differences in the legal environment for personnel selection across a broad range of countries. Whereas some articles in this journal present a point of view that prompts considerable disagreement and challenge from commentators, our article is largely descriptive, and thus, the role of commentators is to expand upon the perspectives offered in our article rather than to take issue with them. We believe that the commentators have accomplished just that and they offer a most useful supplement to our article.

Dunleavy, Aamodt, Cohen, and Schaeffer (2008) offer an explanatory model for the differences across countries in personnel selection practices. Their commentary can be seen as a complement to our article, as it posits some interesting explanations based on the moral, intellectual, and cultural climate of each country (which they refer to as the "zeitgeist"). We find this a useful perspective and suggest that there is value in exploring national culture differences (e.g., in terms of Hofstede's [2001] model) as potential explanatory factors for differences in both laws and their enforcement. In addition, we note that the term zeitgeist implies something rather unstable. However, cultural differences may often be quite stable. For example, our contributing author from Switzerland (König) suggests that the preference for solving conflicts by reaching a consensus, not by going to court, has been a culturally shared attitude in Switzerland for a long time. This attitude may be one reason why legal cases regarding personnel selection in Switzerland are so rare. Another example is the negative attitude toward bureaucracy (or, more precisely, the fear of too much bureaucracy). This fear has long been raised, at least in some European countries, and it may reduce the likelihood that laws are developed that force companies to extensively document issues related to adverse impact. Also, as a potential addition to Dunleavy et al.'s model, we suggest that economic conditions in each country can be 
influential. Most sociological theories would argue that we cannot ignore economic relationships as an important determinant of the legal principles in each country and how the law is implemented and enforced.

A particularly important issue raised by Dunleavy et al. is the distinction between the existence of the law and the enforcement of the law. Many countries have similar laws, but some countries enforce them more effectively than others. Similar to organizational level policies (e.g., performance management), execution is key (Aguinis, 2009). A useful follow-up to Myors et al. would be the study of the extent to which laws are enforced; such a study would provide researchers and practitioners with a more realistic picture of the various environments in addition to knowledge of the laws in existence in each country.

Gutman's (2008) commentary outlines a set of features that help explain why the legal environment for selection is generally better developed and better enforced in the United States than in other countries. We agree with most of his points, but do offer a differing perspective in a few instances. Gutman's first point is that the United States has a history of righting wrongs. He documents the gradual addition of one protected class after another over an extended period of time, and contrasts this with several European Union (EU) countries where there was little history of concern for such protected class issues prior to a mandate that they be addressed as a condition of joining the EU. Whereas this statement is descriptively true, contributing authors from various countries note that the United States is certainly not alone in having a history of righting wrongs, and in the case of offering legal protection to various groups, there are numerous instances of countries with broader sets of protected classes than the United States (our article documents the substantial number of countries in which categories such as sexual orientation, marital status, and political affiliation are included among the protected classes). There are also settings where other countries acted to right social wrongs earlier than the United States. For example, slavery was abolished in the United States in the mid-1860s, whereas it was abolished in Argentina in 1813, in Puerto Rico in the mid-1830s, and in other Latin American countries also earlier than in the United States. Similarly, applicant and employee rights have been recognized in many European countries since the 1920s, and European personnel selection models (e.g., the one by De Wolff \& van den Bosch, 1984) have been in advance of the United States in including applicant decision making as a part of the process. As an additional comment regarding the EU, note that the range of ethnic and other groups across the EU is arguably considerably broader than the groups of major concern in the United States. This will make attempts at legislation enforceable in every country very difficult, with the likely outcome a combination of EU and national legislation (just as the United States has a combination of national and state laws).

Gutman's conclusion is that laws related to personnel selection are strongest in the United States. We believe this is a sound conclusion if the focus is on the structural detail of the regulatory and evidentiary process for pursuing claims under the law, and we believe that this is the interpretation intended by Gutman. But laws in other countries may be viewed as stronger if the reference is to the range of groups protected by law or to the set of methods available to increase employment prospects for members of protected classes (e.g., the availability of preferential treatment as a remedy).

The remaining three commentaries address country-specific issues. Two provide information about countries not covered in our article: Praslova (2008) regarding Russia and Cozma and Woehr (2008) regarding Romania. This additional coverage broadens our perspective and is quite welcome. Premarajan, Thornton, and Pahdi (2008) offer useful amplification and further detail about the legal environment in India beyond what is presented in Myors et al. and point out areas of possible misinterpretation. The initiators and editors of the Myors et al. article (Sackett and Shen) attempted to extract 
useful information in a relatively small number of pages based on much lengthier initial write-ups provided by the authors from each country. Thus, this editing process is responsible for the lack of a full and complete picture. Most points raised by the commentators, such as the distinction between initial selection and promotion in the use of setasides or quotas for protected groups, the citations to studies of group differences, and the lack of regulation in the private sector, were included in the full write-up, and thus, we agree that it is useful for the commentators to raise these points.

That said, we would like to provide certain clarifications with regard to some of their observations. First, the commentators observe, "Article 15 of the Indian Constitution prohibits discrimination in society, but it does not apply to employment in the public sector as Table 2 might suggest." Article 15 specifically addresses prohibition of discrimination on grounds of religion, race, caste, sex, or place of birth. This article also gives powers to the government for making special provisions for women and children. The Myors et al. article had only mentioned certain provisions in the constitution of India having direct or indirect relevance to personnel selection practices. All the articles may not have direct relevance, but some of them, like Article 15, form the basis on which certain provisions such as affirmative action for disadvantaged groups have been made. Second, to our knowledge, no protection is given on the basis of race or place of birth. We addressed the other categories. Third, the statement in the Myors et al. article that psychological assessment as a part of personnel selection is mainly practiced in the armed forces was not meant to imply that elsewhere it is not practiced at all. In the Indian Armed Forces, personnel selection is firmly based on assessment of psychological attributes. This has been the practice for the past 5 decades or more. However, it is a recent development in private organizations. Even though psychometric testing has been recently introduced in recruitment/selection in various private-sector enterprises, the tests that are used are some- times not properly validated. Even in government hiring other than in armed forces, measurement of psychological attributes is not given adequate importance. Fourth, the commentators observe that organizations can rather easily rebut charges of discrimination. They need only to provide evidence that the selection procedures fully comply with organizational procedures. The fuller write-up had mentioned that there are no laws controlling selection/recruitment processes, especially in the private sector.

Finally, in reacting to the commentaries, questions arise as to whether we can turn to particular countries for "best practice" models. We believe that it is most useful to differentiate between "best" in terms of rigor and currency in incorporating the research methods and findings of the personnel selection field and best in terms of optimal policies regarding whom to protect and how to remedy historical wrongs. The first is a scientific question, and one can reasonably compare countries on this standard. The second is a question of values, and there is not a scientific or technical basis for determining whether, for example, a model that prohibits preferential treatment is "better" than a model that permits or requires it. Thus, we assert that it is important to keep this distinction clear and to avoid confounding the two. That a country is sophisticated in its incorporation of the field's technical and scientific knowledge base does not imply that its policies regarding protected classes and remedies are to be preferred to those of other countries.

We close by again thanking the commentators for their useful additions to our understanding of the legal environment for selection. We hope that our focal article together with the commentaries proves useful to selection researchers and practitioners.

\section{References}

Aguinis, H. (2009). Performance management (2nd ed.). Upper Saddle River, NJ: Pearson Prentice Hall. Cozma, I., \& Woehr, D. (2008). International perspectives on the legal environment for selection: Romania case. Industrial and Organizational Psychology: Perspectives on Science and Practice, 1, 260-263. 
De Wolff, C. J., \& van den Bosch, G. (1984). Personnel selection. In P. J. D. Drenth, H. Thierry, H. Willems, \& C. J. De Wolf (Eds.), Handbook of work and organizational psychology (Vol. 1). Chichester, UK: Wiley.

Dunleavy, E. M., Aamodt, M. G., Cohen, D. B., \& Schaeffer, P. (2008). A consideration of international differences in the legal context of selection. Industrial and Organizational Psychology: Perspectives on Science and Practice, 1, 247-254.

Gutman, A. (2008). Legal environment for selection in the United States. Industrial and Organizational Psychology: Perspectives on Science and Practice, 1, 255-257.

Hofstede, G. (2001). Culture's consequences: Comparing values, behaviors, institutions, and organiza- tions across nations (2nd ed.). Thousand Oaks, CA: Sage.

Myors, B., Lievens, F., Schollaert, E., Van Hoye, G., Cronshaw, S. F., M ladinic, A., et al. (2008). International perspective on the legal environment for selection. Industrial and Organizational Psychology: Perspectives on Science and Practice, 1, 206246.

Praslova, L. (2008). The legal environment for selection in Russia. Industrial and Organizational Psychology: Perspectives on Science and Practice, 1, 264-265.

Premarajan, R. K., Thornton III, G. C., \& Padhi, P. K. (2008). Legal environment for selection in India. Industrial and Organizational Psychology: Perspectives on Science and Practice, 1, 258-259. 